\title{
Development of the Future Engineering Education System: New Solutions and Predictions
}

\author{
Nikolay I. Sidnyaev ${ }^{1 *}$, Nadezhda V. Opletina ${ }^{1}$, Yulia I. Butenko ${ }^{1}$, and Elizaveta E. \\ Bolotova $^{1}$ \\ ${ }^{1}$ Bauman Moscow State Technical University, 2nd Baumanskaya str., 5/1, 105005, Moscow, Russia
}

\begin{abstract}
The paper outlines the main predictions for the development of the education system in technical universities related to the emergence of innovative technologies in various fields of science. It is postulated that the education system depends on changes in society. The knowledge, practical skills and personal experience of the students will come to the fore; interest in additional education and self-teaching will increase. It is assumed that in the near future we should expect the development of new methods and technologies of distance learning. The paper deals with the urgent problems of teaching associated with the humanization of engineering education and necessity of student's adaptation to the rapid renewal of professions in connection with the emergence of new information technologies. It is postulated that the interaction of universities with employers is the most important condition for quality training of graduates, which contributes to their successful employment and future career growth.
\end{abstract}

\section{Introduction}

The rapid development of innovative technologies covers the most diverse spheres of life. Constant changes in society largely determine the role of education in the modern world. As we move towards the information society in the field of education, new methods, directions and trends, dictated by scientific and technological progress, appear. Information technology today plays an extremely important role in ensuring information interaction between people, as well as in the systems of preparation and dissemination of mass media. Intelligence, neural networks and other modern technologies in the near future will completely change the education system. Education will be built around new technologies and tools that will make the learning process more flexible and individual.

Each year, new areas of activity and profession appear on the labor market that did not exist before, and the overall picture of the demand for specialists is changing. The higher education system must conform the demands of the time, therefore, every modern university should offer applicants new directions and profiles, and the professional standard of teachers should be filled with new competencies. In 10-15 years, the educational system will undergo significant changes in the teaching methodology: the knowledge and practical

* Corresponding author: sidnyaev@yandex.ru 
skills of students will come to the fore, and portfolio and personal achievements will become more important than grades. Many universities will focus on the practical orientation and development of entrepreneurial skills of students. During teaching, the student will receive diplomas for winning the olympiads, awards for participating in competitions and projects, as well as creating design works and speaking with them, which will give the employer much more information about the professional competence of the young specialist. Own projects will be valued more than subjective and standardized assessments, which cannot give a concrete idea of a person's abilities, but motivate students more than gaining knowledge. It is impossible to accurately predict how the education system will change. It is difficult to imagine what the correct set of knowledge and skills of the future should be, so the main aim of the modern education system is to teach young professionals to adapt to constantly changing conditions, to teach to think and put their knowledge into practice [1].

\section{Continuing education is a priority for the near future}

Education is the main priority and an indicator of the development of all civilized countries of the world. Improving the quality of education is an important task on the way to transforming the existing system of education, which will allow to fully implement the goals and results of students [2]. The formation of a diverse personality with professional skills and competencies, capable of developing and adapting to constantly changing conditions, is one of the main aims of higher education [3]. The most promising concept in the development of teaching practices is the concept of education throughout a person's life. A person must learn to think and act based on the prospects for the economic and social development of the country, the needs of society, modern achievements in science and technology [4]. The aim of developing pre-adaptability - the ability of a person to adapt to completely new conditions for him - is crucial in the preparation of highly qualified specialists. Preadaptation to uncertainty becomes a prerequisite for life in an era of changes. If in the XIX century the craft was handed down from one generation to another, and in the XX century the family dynasties of doctors, lawyers, engineers were adopted, but today the young generation should get used to the need to change the profession several times during life. The pace of renewal is getting higher than the pace of learning, which is why continuity of the educational process, avoiding narrow specializations and emphasizing fundamental education are so important. The issue of the content of education, as well as the relationship between fundamental and applied knowledge, comes to the fore. Improving a person's readiness for change can become a strategic setting of the education system in the situation of a quick renewal of professions and the inability to predict the right set of knowledge and skills of the future. The aim of the education system is not only to train specialties, but also to prepare for continuous learning. Young specialists need to learn to constantly acquire new knowledge in the conditions of scientific and technological progress and the development of new forms of economic and social activity, where the most optimal is the combination of a broad general cultural education with the deep development of specific specialized knowledge [5]. Susceptibility to new challenges and the ability to respond to them promptly and effectively are the skills that a modern specialist in any field of activity needs.

«Continuing education» is a process of continuous improvement of knowledge and skills associated with the necessity to be always in-demand specialist. Such education system focuses on advancing the development of society, a professional career, personal skills and qualities, and assumes the continuity and multivariate nature of general and vocational education. The teacher serves as the organizer of studies and is designed to provide an individual approach to learning. Productive, active-creative teaching methods 
that offer independent and creative activity of a problem-practical nature dominate [6]. The university instills in students a love of knowledge, as well as an understanding of the need to constantly develop and self-study after graduation, to look for new sources of growth and development throughout life. The university does not teach a narrow profession, they develop skills in building the trajectory of their professional life.

Today, people are trying to gradually move away from manual labor. In a modern technological society, automation of processes is increasingly observed, so the need for physical labor is likely to be intensively tending to zero. Most cognitive processes will undergo automation, as the computing power of machines is also growing exponentially. The priorities of teaching will be creative abilities, and the creative class will become the main stratum of society, i.e. people who change society from trends in the economy to the culture of cities and the moral principles of society. These are participants of an economy that requires creative thinking and the ability to solve problems non-standard.

\section{New opportunities of distance learning}

With the level of development and diffusion of modern technologies, information becomes much more accessible, and teaching - cheaper. Today, the availability of the Internet, electronic encyclopedias, manuals and other information resources is not a problem. There are a huge number of online courses that students can take on their own at any convenient time [7]. Fast Internet and process automation allows you to provide online classes, allowing both the teacher and students not to leave their own homes. With rapid steps, we are moving towards individual distance learning. With the help of big data, machines already today track the amount of time spent on tasks, analyze the answers and create individual recommendations. In the future, artificial intelligence will select educational content and teaching methods that are effective individually for each student. The classical form of education is becoming less productive in a rapidly changing world. Many universities are starting to join the Open Education platform, which offers mass online courses in various fields of study without academic requirements for admission, and some universities offer to receive a diploma of higher education remotely. To ensure such education, universities use various methods of distance education: video and audio conferences, video lectures, webinars, Skype classes and others. In addition to simple communication via video (two-way or multi-channel), teachers of the future will use interactive tools that can receive feedback from students and immediately check their knowledge. The learning process will become even more "lively" than in a traditional educational institution. Many people think that learning online courses may not have the best effect on socialization, as school and university allow you to communicate with peers, while online learning deprives schoolchildren and students of this opportunity. However, on the other side of the scale is the fact that distance learning really erases any boundaries: a teacher from the USA can give a lecture for students from the USA, China, Russia and other parts of the world.

Today, the globalization of education is actively developing and provides the opportunity to receive education in any country of the world. The globalization of education has obvious advantages - the young people get the opportunity to study in other countries, choosing an educational institution, a set of disciplines and teachers, or combine studying at home with internships at foreign universities. In this way, future specialists join the world cultural values, enrich their knowledge and their experience, develop professional competencies, while young people get acquainted with other working conditions, with other opportunities for professional and career growth. A serious problem here is the fact that capable young specialists leave their homeland and go to study in another country, while 
distance learning allows you to stay home and get an education in almost any leading university in the world.

An important factor in the development of distance learning will be the prospect of the appearance of machine translation of acceptable quality. The real transformation of the market will come at the time when knowledge of the language will cease to be a barrier to education. In the very near future, study will be much more accessible, faster, more effective and more individual. It will receive a more objective system of assessing personal qualities. We will be able to expect that soon only the most intelligent, talented and creative people will occupy all prestigious posts, regardless of their status.

Today, the cloud computing technology, which serves as some kind of information storage, for example, for completed homework and projects, is actively gaining popularity as part of online education. In the classes of the future, students will simply need an electronic device that will provide access to homework and other learning resources. All materials will be available as long as there is an Internet connection. Such convenience will provide students with a certain freedom, as they can work on projects both at home and anywhere else. The main didactic advantage of using cloud technologies in the educational process is the organization of joint work of teachers and students, which opens up new perspectives that will improve the efficiency of the educational process and, therefore, the better achievement of the goals, since these technologies are high-tech, relevant and promising. Cloud technologies offer an alternative to traditional forms of organization of the educational process, creating opportunities for personal learning, interactive classes and collective teaching. The introduction of cloud technologies will not only reduce the cost of acquiring the necessary software, increase the quality and effectiveness of the educational process, but also prepare the student for life in the modern information society, and help to organize methodical work with teachers in a high-quality and efficient manner.

\section{The role of self-study and retraining in the process of education}

One of the most important changes in the field of education is an active interest in additional education [8]. This direction is growing very quickly and is gradually becoming more significant than higher education, which is no longer considered mandatory for career growth, especially in the field of information technologies. Russian technical universities provide high-quality basic education, but the main problem is the almost complete absence of programs on innovative technologies. Teaching process is often conducted according to outdated programs; graduates lack the professional horizons, technical skills and experience in solving practical problems. Many of them do not understand the connection between theory and practice. If the university does not update the program to the demands of the employer and the market, then each subsequent graduation of students will be doomed to failure - the technical competencies of the specialist will less and less satisfy the demands of employers [9]. Young specialists are looking for new knowledge on the Internet, and the main thing in education is not a content, but context: it is important not to memorize large amounts of information, but to understand how it can come in handy. The value of education and communication with the teacher lies in the fact that he teaches the subject area and context. Many world companies create separate departments in universities, launch courses and trainings for students and teachers on relevant innovative technologies. Theoretical knowledge gained at the university is supplemented by practice and work with experts in specific fields, and ultimately a successful student is hired.

Retraining programs have become more popular. The personal and professional diagnosis of students, focus on cardinal reformatting and rethinking of accumulated experience, has emerged. The dynamism of modern technology requires not a narrow 
specialist, but a specialist who is able to constantly adapt to the new challenges. Upon coming to work, a young specialist must continue to study - this is a requirement of modern technologies. The aim of the university is to teach you to continuously develop and transform the knowledge and skills of building the trajectory of your professional life.

It is also necessary to take into account international competition and competition with the non-university sector. The sources of education are becoming different and the demand for a diploma is gradually declining. Some areas have formal requirements of the relevant document for entering the profession, but for life success a diploma does not always play a significant role. Some personal qualities of a person, a quality education and high working capacity are needed. In the future, it is expected to develop a "non-degree" program that is not integrated into standard educational tracks. These are programs that do not have a degree («Non-Degree Programs»), which allow to get high-quality additional qualifications or practical training in a certain field. They do not give a degree, but confirm the student's knowledge with a certificate («Certificate Programs») or a diploma («Diploma Program»)

Today, a huge amount of opportunities and resources is available to a person to obtain information. In this case, universities only compete with their ability to form a team and educational products. You can assemble almost any educational module of the required quality. This market is competitive not only between universities, but also between researchers, teachers, so the ability to compete with educational models is becoming more important. The main aim of Bauman Moscow Technical University is to understand the development trends of education. Universities of the first generation grew the intellectual elite, universities of the second generation - a mass of educated people for an industrial society. Universities in the digital world that has emerged from the industrial model, a world in which technological change does not occur from generation to generation, but within the framework of one generation several times, cannot learn craft or profession. In the third generation of universities, one must learn the ability to find the best path for the development of oneself, organizations, the country and the world.

\section{Humanization of engineering education as a factor of student's personal qualities development}

The modern direction in the field of education has become the preference for educational results "Soft skills" and "Hard skills". "Hard skills" is a set of professional skills and abilities related to the technical side of activity. Such skills can be demonstrated, they are mandatory requirements for hiring. "Soft skills" are associated not only with a specific type of activity, but with communications for effective interaction with colleagues, clients and partners. Such skills are often called "personal qualities", emphasizing the direct relationship between "soft skills" and a person's character, temperament and personal experience. The student can improve his "hard skills" with the help of training centers universities, schools, and continuing education courses. These skills are characterized by segmentation into several difficulty levels. Studying each of the levels ends with an exam. "Soft skills" are acquired through personal experience, through trial and errors. Personal and background trainings, master classes and communication will help speed up development. Self-training and development in the process of work, corporate training programs also positively affect the development of such skills.

It is believed that the career-forming result of education is the personal qualities of the graduate, such as creativity, initiative, communication, teamwork. However, the ability to properly represent yourself and the ability to be a professional do not replace each other, therefore, one of the aims of modern education is the ability to teach students to combine "Hard skills" and "Soft skills" - professional skills and personal experience. 
Communicativeness and other well-known "soft skills" remain the most important competencies. It is necessary to teach future specialists to search for information, to be sociable and creative, and be able to work in a team. Our predecessors in the middle of the twentieth century conducted a creative search for such competencies. The growing flow of scientific information must be able to systematize, process and transmit to students in such a way as to prepare them for the new equipment and technological processes with which they will deal when they come to life. It is important to note that the university should give not only the sum of specific knowledge, but also teach to draw independent conclusions on the basis of this knowledge, instilling in young specialists creative thinking skills. Such skills are successfully helped to develop the system of humanization of education - the development of cultural components of the content of education, the formation of personal maturity of future specialists [10]. The synthesis of the humanitarian and technical components in the education system of technical universities allows a person to develop comprehensively. The establishment of a harmonious balance between naturalmathematical and humanitarian cycles in learning develops in each learner a spiritually rich and versatile personality.

The lifestyle of a modern person is associated with the functioning of various technical devices, which leads to the recognition of the decisive role of technical means and scientifically based technical knowledge in the process of social development of society. In this regard, the underestimation of spiritual culture leads to negative consequences: increased socio-economic contradictions, as well as dehumanization of public life in general. Science and technology are not important in their own right, but only to the extent that they contribute to the development of the individual's creative abilities, the realization of inner wealth and various possibilities [11].

An engineer cannot work effectively if he does not know how society and the economy work. Moreover, humanitarian disciplines develop creative thinking, which is necessary for any modern specialist. For example, psychology helps students of technical specialties develop professional communication skills, history promotes orientation in an everchanging world, develops thinking and analytical abilities, and a speech culture helps to correctly express thoughts. Today, students cannot do without foreign languages, which contribute to the career growth of young specialists and the development of international relations, make it possible to participate in international conferences. Such humanitarian subjects can significantly expand the horizons of students. The university is not only an educational, but also a cultural center, which introduces students to universal values and contributes to the formation of spiritual qualities. Educational, developmental and educational functions are those components that a qualitatively built education system should combine.

\section{The interaction of universities with employers as the main factor of quality training of graduates}

The deficit of specialists in key areas for digitalization may become one of the main negative factors hindering the development of the digital economy. In the very near future, it will be necessary to ensure a high level of basic digital literacy of the population and to have time to train as many specialists with advanced digital skills as possible, and in addition, motivate them to stay in the country and engage in local projects. The situation on the labor market is characterized by high demands placed by the employer on young specialists. Only a highly skilled worker who knows his job and has all the necessary professional competencies is able to withstand high competition. Successful professional development is possible only on the basis of a conscious choice of path, on the basis of 
desires and opportunities. It is important to have the desire to overcome difficulties, to realize the possibilities of one's professional and personal growth.

One of the serious problems of modern education is the interaction of students with employers. This is a complex process consisting of stages, forms, methods and processes that are different in content, the purpose of which is to train personnel focused on innovative activities. In order for graduates not to have difficulties in the first years of work at the enterprise, it is necessary to bridge the big gap between theoretical knowledge and what is expected from graduates in practice. It is through the partnership between universities and enterprises that the high-quality practical training of university students is enhanced, and for the enterprise, elements of innovativeness, variability, and structuredness are introduced. Obviously, both parties are interested in establishing close contacts. They enable the university to monitor the changing requirements of enterprises of various industries for specialists and to promptly adjust educational programs, which in turn helps to increase the competitiveness of the educational institution. At the same time, enterprises have the opportunity to get specialists trained according to their requirements.

Implementation of innovative educational programs by universities is impossible without a strategic partnership with employers aimed at long-term cooperation. The purpose of the partnership is to ensure high quality professional training of specialists on the basis of comprehensive cooperation of the university with interested enterprises and organizations - strategic partners by combining intellectual potential, material, financial and corporate resources. A strategic partnership between a university and an enterprise refers to bilateral contractual relations containing the following characteristic elements:

- long-term training program for specialists for the enterprise, taking into account the prospects for its development;

- the target component of student training, implemented jointly by the university and the enterprise, including advanced training for the development of new types of products and technologies;

- creation of a base for conducting production, technological and undergraduate practices of students;

- conducting joint research and development work, attracting university scientists to create and transfer innovative products;

- creation in the university of a modern educational and research laboratory base;

- targeted training for the company of highly qualified personnel;

- creation of joint scientific, educational and innovative structures.

Thus, the strategic partnership should provide high-quality and relevant targeted training and professional development of specialists, increase the competitiveness of the university in the labor market and educational services, improve the quality of professional training and competitiveness of graduates.

The most traditional way of interaction between employers and students is a work-based experience. It is still one of the most popular ways, as removes the contradiction between the prevailing forms of training and the interests of the students themselves. The controversy grows to senior courses, when in universities, attendance at a number of disciplines drops sharply. Students at this time prefer to undergo practice, on which they got a job independently, or to work (often not in their specialty). The way out is to organize a system of interaction between the university and future employers, that is, enterprises where students could perform work on their profile. The practice is designed to consolidate the theoretical knowledge and skills acquired in the learning process, becoming the starting point of a professional career for many students.

Now one of the main directions related to education is the creation of joint centers or laboratories with universities and organizations whose task is to develop and test new technologies in accordance with specific tasks. Over the past few years, 12 Next Gen Lab 
innovative laboratories have been opened at the largest universities in Russia: Moscow Technological University (MIREA), Gubkin Russian State University of Oil and Gas, Higher School of Economics campus in Moscow and Nizhny Novgorod, Tyumen Industrial University. Laboratories become venues for lectures and innovative projects. Students work on tasks in which the largest Russian companies are interested. Future specialists are testing their ideas, and any failures enrich students with new experience and knowledge. Thus, the graduate does not notice the end of the university and the transition to professional activity, because in senior years he is connected with his employer. Bauman Moscow State Technical University already has such educational formats, for example, joint programs with academic research institutes and other corporations, where the transition really becomes smooth.

\section{Demands for the future professions}

In the foreseeable future, there will be a polarization of qualified and unskilled professions. A person should be ready for training that will last a lifetime. In the field of modern education, we are faced with the fact that people are increasingly forced to change jobs, areas of activity and specialties [12-13]. Here the forecasts of Russian and foreign futurologists can be given. Experts are confident that engineering specialties will not lose their popularity in the foreseeable future, and one of the most promising areas in engineering will be the creation and maintenance of automated systems and robots. This direction will include a whole set of individual specialties - the creators of home robots, industrial robots, medical robots and entertainment robots. Virtual reality architects, information system developers, data specialists, interface developers, artificial intelligence specialists and other professionals of the digital age will be in stable demand in the near future

To master such professions, a future specialist should be well versed in automated systems, programming, process control, not to mention fundamental knowledge in the fields of physics, mechanics, and electrical engineering. We have compiled a list of the most interesting specialties for the next half century, which will be extremely popular in the future. These are professions in various fields of knowledge, such as an online therapist, an operator of remote surgery, a specialist in brain implants (in the field of medicine); an architect of living systems, an operator of "smart" waste recycling (in the field of biotechnology); alternative energy consultant, operator of underground drone drifters, developer of energy micro-generation systems (in the field of energy and resources); infrastructure designer of a smart home, builder of underwater cities, architect of energyautonomous buildings (in the field of construction); pilot of commercial spacecraft, a guide in the field of space tourism, a developer of minerals in space, a cleaner of space debris (in the field of space) and many others.

In the next 20 years, the demand for specialists in unmanned systems will grow. In parallel, a lot of specializations will appear - drone developers for various purposes (military, postal, surveillance, engineering), unmanned vehicle developers, underwater drones developers and machine control interfaces. At the same time, developers of intelligent systems, dispatchers for organizing UAV flights will be in demand. A separate specialty will be the analytics of the data collected by drones.

Today, professions related to database architecture and information security are actively gaining popularity. The huge amounts of data accumulated on the hard drives of the servers must not only be compiled and collected, but also processed and systematized. In the future, the volume of information will only increase, and the number of specialists required to maintain and protect databases will grow in arithmetic progression. This kind of activity involves designing databases, developing principles and algorithms for its operation, 
optimizing the user's quick access to the necessary information, monitoring the speed of the machine's response and the safety of the accountable information.

Creating virtual universes in which people can instantly immerse themselves with the help of special glasses is another promising direction for the future. The development of virtual objects, drawing their shape and texture, endowing them with physical properties that are as similar as possible to their real counterparts is a very complex and timeconsuming process. Huge teams of specialists are working on each such project, performing tremendous amounts of work. Creating a small virtual universe with limited functionality requires a lot of time and effort.

In the near future, the active development of the Internet of Things technology is expected, which will require new creative and creative specialists in the field of information technology. The «Internet of Things» is a concept that combines all the information stored on the world network from household and other equipment used by a person in everyday life. The number of such intelligent equipment is constantly growing, and the need for new specialists who will study a large amount of data generated by home appliances, devices from the office or car is also growing. Such an analysis will require specialist knowledge of statistics, marketing and programming. For students planning to associate a future profession with the analysis of information from smart technology, new curricula are already being developed. For example, in 2012, the Internet of Things Laboratory was opened at the St. Petersburg University of Telecommunications, and new disciplines were added to training courses. Similar programs appear in other leading universities around the world.

The demand for quality engineers of various specializations will only grow, especially in the manufacturing sector. Optimization of various processes, the emergence of innovative developments and technologies in production will automatically provoke demand for new specialists. Globalization, automation of manual labor, technological progress and digitalization, requiring the acquisition of new skills, will become the main factors that will disappear in such professions as accountants, drivers, cashiers, travel agents, copywriters, proofreaders, bank tellers, translators, librarians and many others.

\section{Conclusion}

The fourth industrial revolution is a predictable event that will leave an indelible mark on the history of education. Changes in the field of education are inextricably linked with the processes taking place in the scientific, cultural, socio-political and economic life of the world community. In the near future, distance learning methods and technologies will be actively developed, students will be able to choose interesting areas for self-study with a virtual visit to lectures and conferences. A large number of different electronic resources will make learning accessible, flexible and effective, allowing not only to quickly receive information, but also to develop thinking and give people the opportunity to solve creative tasks in a new way [14-17].

Education is the foundation of sustainable development of the country, therefore improving the quality of education is one of the most urgent tasks of modern society. Educational institutions should teach students the ability to find the best path for themselves, organizations, enterprises, countries and the world at any given time. The student's knowledge and ability to put this knowledge into practice in combination with personal experience should come to the fore. The inclusion of workshops in the curriculum to obtain the skills necessary for employment and the use of laboratory technologies for this is a key factor in the development of modern education. Critical thinking [18-20], the application of technical knowledge and skills in the process of teamwork are necessary for young professionals who begin careers in companies. Education, which consists in the 
formation of stereotypical thinking and the acquisition of traditional knowledge, prevents the student from unleashing his full potential and showing his true capabilities. The modern education system should not be overly standardized. If such a system does not allow deviations from the norm, then it hinders the development of creativity and creativity.

An equally important task is the ability to adapt to constant changes in society and the desire to receive additional education in the field of relevant innovative technologies. A young specialist who has gained knowledge and wants to become a highly qualified specialist must independently learn to apply and use existing knowledge, be creative in his professional activity, make scientifically based decisions in a rapidly changing world.

\section{References}

1. N.I. Sidnyaev, Modern problems of elite engineering education, Mechanical engineering and engineering education, Vol. 3, pp.64-74 (2014)

2. N.V. Opletina, Engineering activity and technological progress, Genius V.G. Shukhov and the modern era: materials of the International Congress. N.G. Baghdasaryan, E.A. Gavrilina, pp. 274-278 (2015)

3. E.A. Bocharnikova, S.P. Muravyova, O.V. Parshina, Education of the future: difficulties and prospects, Pedagogy: traditions and innovations: materials of the XI Intern. scientific conf., Kazan, September 2019, pp. 1-3. Kazan: Young Scientist (2019)

4. A.N. Perezhovskaya, Continuing education: goals, objectives, content, functions, development prospects, Problems and prospects of the development of education: materials of the VI Intern. scientific conf., Perm, April 2015, pp. 38-41, Perm: Mercury (2015)

5. G. Abilkasimova, R. Dzhumasaeva, Continuing professional education as an improvement in the quality of training of specialists, International Journal of Applied and Fundamental Research, Vol. 12-5, pp. 897-901. (2016)

6. I.K. Kornilov, Engineering education of the future: new meanings, Russia: trends and development prospects, Vol. 12-1, pp. 887-889 (2017)

7. V.G. Ivanov, Yu.P. Pokholkov, A.A. Kaybiyinen, Yu.N. Ziyatdinova, Ways of development of engineering education: the position of the global community, Higher Education in Russia, Vol. 3, pp. 67-79 (2015)

8. E.A. Sokolova, The future of higher education in Russia: a review of development forecasts, Personality in a changing world: health, adaptation, development, Vol. 3, pp. 61-69 (2013)

9. G.E. Veselov, N.A. Lyz, A.E. Lyz, Building the future: the experience of phased improvement of engineering education, Higher Education in Russia, Vol. 5, pp. 15-22 (2017)

10. L.G. Savenkova, Humanitarian education and innovative learning technologies, Bulletin of Moscow State University of Culture and Arts, Vol. 3 (65), pp. 203-211 (2015)

11. G.E. Loginova, Problems of the humanitarization of higher education in modern Russia, Bulletin of KemSU, Vol. 4-1 (64), pp.87-89 (2015)

12. S.A. Rojala, Beyond 2020: Preparing engineers for the future, Proceedings of the IEEE. pp. 1376-1383 (2012) 
13. V.G. Ivanov, A.A. Kaybiyaynen, I.M. Gorodetskaya, Engineering education for "Flexible, viable and stable society", Higher education in Russia, Vol. 12, pp. 60-69 (2015)

14. I.D. Belonovskaya, E.M. Yezerskaya, Formation of the future engineer's readiness to manage production and technological risks, Bulletin of the Samara State Technical University, Series: Psychological and Pedagogical Sciences, Vol.1 (25), pp. 32-41 (2015)

15. N. Cavus, Distance learning and learning management systems, Procedia-Social and Behavioral Sciences, Vol. 191, pp. 872-877 (2015)

16. E.N. Zaborova, I.G. Glazkova and T.L. Markova, Distance learning: Students' perspective, Sociological Studies, Vol. 2(2), pp.131-139 (2017)

17. T. Markova, I. Glazkova and E. Zaborova, Quality issues of online distance learning, Procedia-Social and Behavioral Sciences, Vol. 237, pp. 685-691 (2017)

18. R.W. Paul, Critical thinking and the critical person, Thinking, pp. 373-403, Routledge (2018)

19. G. Dunne, Beyond critical thinking to critical being: Criticality in higher education and life, International Journal of Educational Research, Vol. 71, pp. 86-99 (2015)

20. G. Ladson-Billings, W. F. Tate, Toward a critical race theory of education, Critical race theory in education, pp. 10-31, Routledge (2016) 